\title{
Psychiatric disorders in general paediatric referrals
}

\author{
M E GARRALDA AND D BAILEY
}

Booth Hall Children's Hospital, Manchester

SUMMARY Detailed interviews with parents of 128 children aged 7 to 12 years consecutively referred to general paediatric clinics identified psychiatric disturbance in $36(28 \%)$ of the children. Emotional disorders were the commonest psychiatric diagnoses (present in two thirds); less frequent diagnoses were conduct disorders $(5 / 36,14 \%)$, mixed conduct/emotional disorders (six, $17 \%$ ), and hyperkinetic syndrome (three, $8 \%$ ). Disturbance was related to level of energy, with disturbed children being described significantly more frequently as 'bounding with energy' or conversely 'tired and apathetic'. Psychosocial problems (broken homes, mentally distressed mothers, family stress including financial stress and marital difficulty) were also increased in the disturbed group, but most of all these mothers reported feeling stressed in relation to the children.

Psychiatric disorders, particularly emotional disorders, are common associated problems in paediatric referrals. Family stress, specially that focused on parenting, is likely to be an important factor contributing to disturbed children's consultations in general paediatric clinics.

Child mental health problems are a common reason for consultation in general paediatric clinics. They have been reported as the main reason for attending in between 5 to $10 \%$ of children in several surveys. ${ }^{1-5}$

There are indications that childhood psychiatric morbidity may also be present as an associated or background factor in children with somatic presentations, ${ }^{6}$ but recognition of these behavioural problems by physicians is probably limited. ${ }^{7}$ In contrast with the work done in adult medical patients, which has documented psychiatric morbidity in between a quarter and $40 \%$ of medical patients and physician recognition rates of between $40-50 \%$, these issues have received little direct research attention in the paediatric literature.

More information on the frequency, nature, and associations of childhood psychiatric morbidity among paediatric patients is clearly necessary if these problems are to be recognised and attended to, if appropriate, in paediatric clinics.

Two studies have used child behavioural questionnaires completed by parents in children attending general paediatric clinics and reported high rates of psychological deviance in over $35 \%$ of children. ${ }^{9} 10$ The use of these questionnaires has, however, important limitations as they cannot ascertain whether the identified psychological symptoms reflect the existence of psychiatric syndromes that are appreciable and handicapping to the child as opposed to more trivial difficulties. The results therefore need replicating with more robust methodology assessing child psychiatric disturbance with valid research interviews.

We used such a procedure to study attendances to general practitioners of children 7 to 12 years of age. Mental health problems were the main reason for the presentations in $2 \%$ but psychiatric disturbance was present in $23 \%$ of children in most cases as a background or associated factor to somatic presentations. ${ }^{11}$ Our findings indicated that disturbed children consulted more than other children and disturbance tended to be linked to a variety of presentations such as hayfever, bedwetting, nosebleeds, and scabies. They also suggested that family stress, and a particularly pronounced parental concern about disturbed children and their behaviour, might have sensitised these parents towards their children's physical symptoms and contributed to their increased consultations.

We have extended this enquiry to examine the contribution of psychiatric problems at the paediatric outpatient clinic. In this paper we present data obtained from detailed psychiatric interviews with the parents to assess: (i) the frequency and nature of childhood psychiatric disorder in this setting and (ii) the associations of disturbance with somatic symptomatology, as well as with psychosocial family difficulty. 


\section{Subjects and methods}

Consecutive new referrals of children aged 7 to 12 years to general paediatric clinics were selected for study. The children attended clinics run during 1986-7 by six consultant paediatricians with clinical responsibilities in four health districts covering a mixed population in Greater Manchester and Cheshire. Two districts were in city urban or suburban areas and the other two covered medium sized industrial towns and the surrounding rural areas. Only routine referrals entered the study; casualty referrals and those attending special interest clinics were not included and, to avoid language difficulties in completing questionnaires and interviews, children of immigrant families were also excluded.

Parents (mostly mothers) of eligible children were approached at the time of their first visit to the paediatric clinic. They were asked to complete questionnaires and their permission obtained to be interviewed at home. The questionnaires and interview inquired about demographic factors, presenting complaints, other somatic symptoms, recent medical contacts, and developmental problems in the child (modified child health questionnaire ${ }^{12}$ ), about child psychiatric symptoms, and about family function and stress.

ASSESSMENT OF PSYCHIATRIC DISORDER IN THE CHILD To assess psychiatric disorder a clinicodiagnostic approach was used whereby detailed information about childhood psychiatric symptomatology was obtained systematically from the parents and a clinical diagnosis was made by a child psychiatrist (MEG) on the basis of this information. The recently revised version of the psychiatric interview with the parents was used. ${ }^{12}$ This instrument has been used extensively in previous epidemiological studies of childhood psychiatric disorder, it has good inter-rater reliability and it has been found to be the best single method to assess disorder in children. ${ }^{11} 12$

For this interview, the parents are asked whether they feel the child has emotional or behavioural difficulties or nervous trouble and then systematically about the main clinically relevant areas (behaviour, emotions and social relationships, somatic symptomatology). Enough information is obtained to assess not simply whether the symptoms are present, but whether they are severe and handicapping. The diagnosis of psychiatric disorder requires the presence of an abnormality of behaviour, emotions, or relationships continuing up to the time of assessment and sufficiently pronounced or prolonged to cause handicap to the child himself and distress or disturbance in the family or community. ${ }^{12}$ It excludes minor or trivial behavioural problems, which may not deserve specialist attention and also pure 'psychosomatic' or learning problems and mental retardation. In this study, if the child had a disorder, it was classified according to the main symptomatology into emotional, conduct, mixed conductemotional disorders, hyperkinetic syndrome, or any other appropriate child psychiatric conditions according to the International Classification of Disease, 9 th edition (ICD9). ${ }^{13}$

The reliability of the research psychiatrist's assessments from the psychiatric interview with parents was tested in our previous study of psychiatric disorder among children attending general practice. ${ }^{11}$ Twenty schedules were scored independently and blindly as to psychiatric state by another child psychiatrist. The overall agreement for the presence or absence of disorder was $80 \%$, a similar rate to previous reports, ${ }^{12}$ with an acceptable $x$ coefficient of $0 \cdot 6$.

As previous studies have employed questionnaire information to assess psychological problems in children, we used the child behavioural parental scale $A$ and teacher scale B for comparison purposes with these studies and to supplement the parental with school based information. ${ }^{12}$ These scales consist of a list of symptoms or items whose relative frequency and severity is rated on a three point scale if it has occurred in the previous year. A total score is computed: scores of 13 or more (parental scale) and of 9 or more (teacher scale) are regarded as indicating psychological problems in the child and high risk for psychiatric disorder.

ASSESSMENT OF FAMILY STRESS AND DYSFUNCTION

We assessed parental mental health using the general health questionnaire ${ }^{14}$ and we enquired about other family health problems. To assess contemporary psychological stresses, difficulties, and supports in the family, we used the social stress and supports interview. ${ }^{15} 16$ This inquires from the mother about current stresses and supports in several domainswork, finances, housing, social life with relatives and friend, marriage, and children. The degree of stress and support in each of these areas is rated on a four point scale and total psychosocial stress and supports scores are computed.

\section{INFORMATION FROM THE PAEDIATRICIAN}

Paediatricians were asked to note the referring complaint, their diagnosis, and comments about any associated psychological problems to the presentations. The reasons for consultation were classified according to the International Classification of 
Health Problems in Primary Care,${ }^{17}$ which generally correspond with ICD 9 scores. ${ }^{13}$

In the analysis of data, tests of statistical significance were used as appropriate $\left(\chi^{2}\right.$ with Yates's correction in fourfold tables and non-parametric tests for continuous variables).

\section{Results}

The main characteristics of the sample entering the study have been reported elsewhere. ${ }^{18} \mathrm{~A}$ total of 137 parents of children aged 7 to 12 years were approached for this study and $128(93 \%)$ agreed to take part and completed questionnaires. Subsequently two parents declined to be interviewed and 126 interviews were therefore completed. Paediatricians completed questionnaires for 127 subjects and teacher questionnaires were obtained for 100 subjects.

Of the 128 children entering the study there were 66 boys and 62 girls and the mean age for the group was $9 \cdot 1$ years. Most children $(103,80 \%)$ were taken to the hospital by their mothers. Most $(120,93 \%)$ had been referred by their general practitioners and few had been seen by a medical specialist previously $(19,15 \%)$. The main paediatric diagnoses, accounting for half the presentations were: migraine, asthma, abdominal pains, urinary tract infections, growth failure, bedwetting, blackouts, headaches, and soiling. The rest of the children were given one of another 34 diagnoses. Most complaints were long standing and episodic. Mental health problems (that is, behaviour, disorder, anxiety, nigthmares) were the main referring reason in four $(3 \%)$.

\section{PSYCHIATRIC DISORDER ASSESSED FROM PARENTAL INTERVIEWS}

From the information obtained in the psychiatric interview with the parent, psychiatric disorders were judged to be present in $36(28 \%)$ of the children. Disturbed children did not differ from the rest in age: mean (SD) ages were $8.7(1.6)$ and $9.3(1.5)$ respectively, or in sex distribution.

By far the most common psychiatric diagnosis (present in two thirds of disturbed children) was emotional disorder. Other diagnoses included conduct disorder $(5 / 36,14 \%)$, mixed conduct/emotional disorder (six, 17\%) and hyperkinetic syndrome (three, $8 \%$ ). In two thirds of disturbed children the problems were reported both at home and in school, but in one third they were confined to the home. Most problems were long standing: in over $90 \%$ they had lasted more than a year and in two thirds more than three years. The disturbance was judged to be particularly severe (symptoms rated as severe and highly handicapping or multiple) in one fifth of

Table 1 Psychiatric symptoms in disturbed children: emotional symptoms and relationship problems

\begin{tabular}{|c|c|c|c|c|}
\hline & $\begin{array}{l}\text { Symptoms }(1, \text { mild or } \\
2 \text {, pronounced })\end{array}$ & $\begin{array}{l}\text { Disturbed } \\
(n=36)\end{array}$ & $\begin{array}{l}\text { Non-disturbed } \\
(n=90)\end{array}$ & Statistics \\
\hline \multicolumn{5}{|c|}{ No (\%) with emotional symptoms: } \\
\hline Worrying & $\begin{array}{l}1 \\
2\end{array}$ & $\begin{aligned} 9(25) \\
14(38)\end{aligned}$ & $\begin{array}{l}33(36) \\
10(11)\end{array}$ & $\begin{array}{l}\chi^{2}=12.82 \mathrm{df} \\
\mathrm{p}<0.01\end{array}$ \\
\hline Fears & $\begin{array}{l}1 \\
2\end{array}$ & $\begin{aligned} 8(22) \\
22(61)\end{aligned}$ & $\begin{array}{l}24(26) \\
23(25)\end{array}$ & $\begin{array}{l}\chi^{2}=15.72 \mathrm{df} \\
\mathrm{p}<0.001\end{array}$ \\
\hline Irritability & $\begin{array}{l}1 \\
2\end{array}$ & $\begin{array}{l}19(52) \\
15(41)\end{array}$ & $\begin{array}{l}69(76) \\
6(6)\end{array}$ & $\begin{array}{l}\chi^{2}=21.62 \mathrm{df} \\
\mathrm{p}<0.001\end{array}$ \\
\hline $\begin{array}{c}\text { Chronic unhapp } \\
\text { Episodic } \\
\text { Persistent }\end{array}$ & & $\begin{array}{l}5(13) \\
7(19)\end{array}$ & $\begin{aligned} 13 & (14) \\
2 & (2)\end{aligned}$ & $\begin{array}{l}\chi^{2}=11.52 \mathrm{df} \\
\mathrm{p}<0.01\end{array}$ \\
\hline \multicolumn{5}{|c|}{ No (\%) with problems in relationships: } \\
\hline With mother & $\begin{array}{l}1 \\
2\end{array}$ & $\begin{array}{l}10(27) \\
15(41)\end{array}$ & $\begin{aligned} 17 & (18) \\
4 & (4)\end{aligned}$ & $\begin{array}{l}\chi^{2}=33.12 \mathrm{df} \\
\mathrm{p}<0.001\end{array}$ \\
\hline With siblings & $\begin{array}{l}1 \\
2\end{array}$ & $\begin{array}{l}10(27) \\
14(38)\end{array}$ & $\begin{aligned} 19 & (21) \\
2 & (2)\end{aligned}$ & $\begin{array}{l}\chi^{2}=35 \cdot 22 \mathrm{df} \\
\mathrm{p}<0.001\end{array}$ \\
\hline With peers & $\begin{array}{l}1 \\
2\end{array}$ & $\begin{array}{l}10(27) \\
13(36)\end{array}$ & $\begin{aligned} 11 & (12) \\
2 & (2)\end{aligned}$ & $\begin{array}{l}\chi^{2}=35.42 \mathrm{df} \\
\mathrm{p}<0.0001\end{array}$ \\
\hline With teachers & $\begin{array}{l}1 \\
2\end{array}$ & $\begin{array}{l}5(13) \\
5(13)\end{array}$ & $6(6)$ & $\begin{array}{l}\chi^{2}=15 \cdot 3 \\
2 \text { df } p<0 \cdot 001\end{array}$ \\
\hline
\end{tabular}


Table 2 Psychiatric symptoms in disturbed children: activity and antisocial behaviour

\begin{tabular}{|c|c|c|c|c|}
\hline & $\begin{array}{l}\text { Symptoms }(1, \text { mild or } \\
2, \text { pronounced })\end{array}$ & $\begin{array}{l}\text { Disturbed } \\
(n=36)\end{array}$ & $\begin{array}{l}\text { Non-disturbed } \\
(n=90)\end{array}$ & Statistics \\
\hline $\begin{array}{l}\text { Activity-No (\%) who are: } \\
\text { Overactive at home }\end{array}$ & $\begin{array}{l}1 \\
2\end{array}$ & $\begin{array}{r}4(11) \\
11(30)\end{array}$ & $\begin{aligned} 13 & (14) \\
5 & (5)\end{aligned}$ & $\begin{array}{l}\chi^{2}=14.52 \mathrm{df} \\
\mathrm{p}<0.001\end{array}$ \\
\hline Restless at home & $\begin{array}{l}1 \\
2\end{array}$ & $\begin{array}{r}6(16) \\
20(53)\end{array}$ & $\begin{aligned} 19 & (21) \\
8 & (8)\end{aligned}$ & $\begin{array}{l}\chi^{2}=39 \cdot 3 \\
2 \text { df } p<0.001\end{array}$ \\
\hline Restless elsewhere & $\begin{array}{l}1 \\
2\end{array}$ & $\begin{array}{l}3(8) \\
5(13)\end{array}$ & $\begin{array}{l}2(2) \\
1(1)\end{array}$ & $\begin{array}{l}\chi^{2}=12.22 \mathrm{df} \\
\mathrm{p}<0.01\end{array}$ \\
\hline $\begin{array}{l}\text { Antisocial behaviour: } \\
\text { No }(\%) \text { who are stealing }\end{array}$ & $\begin{array}{l}1 \\
2\end{array}$ & $\begin{array}{l}4(11) \\
5(13)\end{array}$ & $\mathrm{3}^{3(3)}$ & $\begin{array}{l}\chi^{2}=16.62 \mathrm{df} \\
\mathrm{p}<0.001\end{array}$ \\
\hline
\end{tabular}

the children with the rest having less severe difficulties. Most parents of disturbed children (two thirds) said that they thought their children had emotional or behavioural difficulties but $10(28 \%)$ felt they had no problems.

The psychiatric symptoms that differentiated disturbed from non-disturbed children at high significant levels $(p<0 \cdot 01)$ are given in tables 1 and 2 . They included fears, worrying and irritability, unhappiness, problems in relationships (table 1), overactivity, restlessness, and stealing (table 2). Additional symptoms present significantly more commonly in the disturbed group $(p<0.05)$ were tantrums, loneliness, obsessionality, worrying about health, problems in the relationship with fathers, overactivity outside the home, aggression, destructiveness, and lying. School refusal was exclusively present in a minority of disturbed children (mildly in five $(13 \%)$ and pronounced in one $(2 \%))$.

In line with the findings from the psychiatric interviews, both the parental and school behavioural questionnaire scores discriminated disturbed and non-disturbed children (parental mean (SD) scores of $16 \cdot 1(6 \cdot 7)$ and $9 \cdot 5(4 \cdot 7)$ respectively, $\mathrm{p}<0 \cdot 0001$; teacher mean scores of $9.4(7.5)$ and $3.8(3.8)$, $\mathrm{p}<0.001)$. High scores indicative of psychological deviance were obtained in $46(35 \%)$ (parental questionnaires) and 23/100 (23\%) (teacher questionnaire) of the children.

Although both the psychiatric interview with parents and the parental behavioural questionnaires used parents as informants, they did not necessarily identify the same children as disturbed. Thus the predictive value of the questionnaire (children identified as disturbed who turned out to be disturbed also from the interview assessments) was $59 \%$. Its sensitivity (disturbed children from interviews also identified by the questionnaires) was $70 \%$ and its specificity (non-disturbed children from interviews identified as disturbed by the questionnaires) $20 \%$.

Prior help for psychiatric difficulties was the exception rather than the rule and only four $(11 \%)$ disturbed children had had psychiatric contact. However, three $(8 \%)$ had consulted their general practitioner for psychological symptoms in the three months before assessment.

\section{ASSOCIATION BETWEEN PSYCHIATRIC DISORDER AND} SOMATIC SYMPTOMS

As most disturbed children $(27,75 \%)$ consulted for physical problems, we were interested in examining whether certain physical diagnoses were more frequent in the disturbed group. We also wished to examine from the child health forms whether disturbed children had experienced more recent somatic complaints and had more recent contact with medical services. Our results of this analysis were mostly negative. The only illness feature to discriminate the two groups was level of energy: 62 out of $90(68 \%)$ of non-disturbed children had normal energy as compared with 15 out of $36(41 \%)$ disturbed children. Of those disturbed $13(36 \%)$ had high and eight $(22 \%)$ low energy levels, while for the rest of the children the numbers were $20(22 \%)$ and two (2\%) respectively with an additional two children having variable energy levels reported $\left(\chi^{2}=11 \cdot 4,3 \mathrm{df}, \mathrm{p}=0 \cdot 009\right)$. There was also a trend for more parents of disturbed children to think that the children's somatic symptoms were aggravated by the child being under psychological pressure (for example, schoolwork or exams: four $(11 \%)$ compared with two (2\%)) and by upsets (for example, worry, anger or trouble: eight $(22 \%)$ compared with 11 $(12 \%))$. 
Table 3 Psychosocial aspects in children with psychiatric disorder

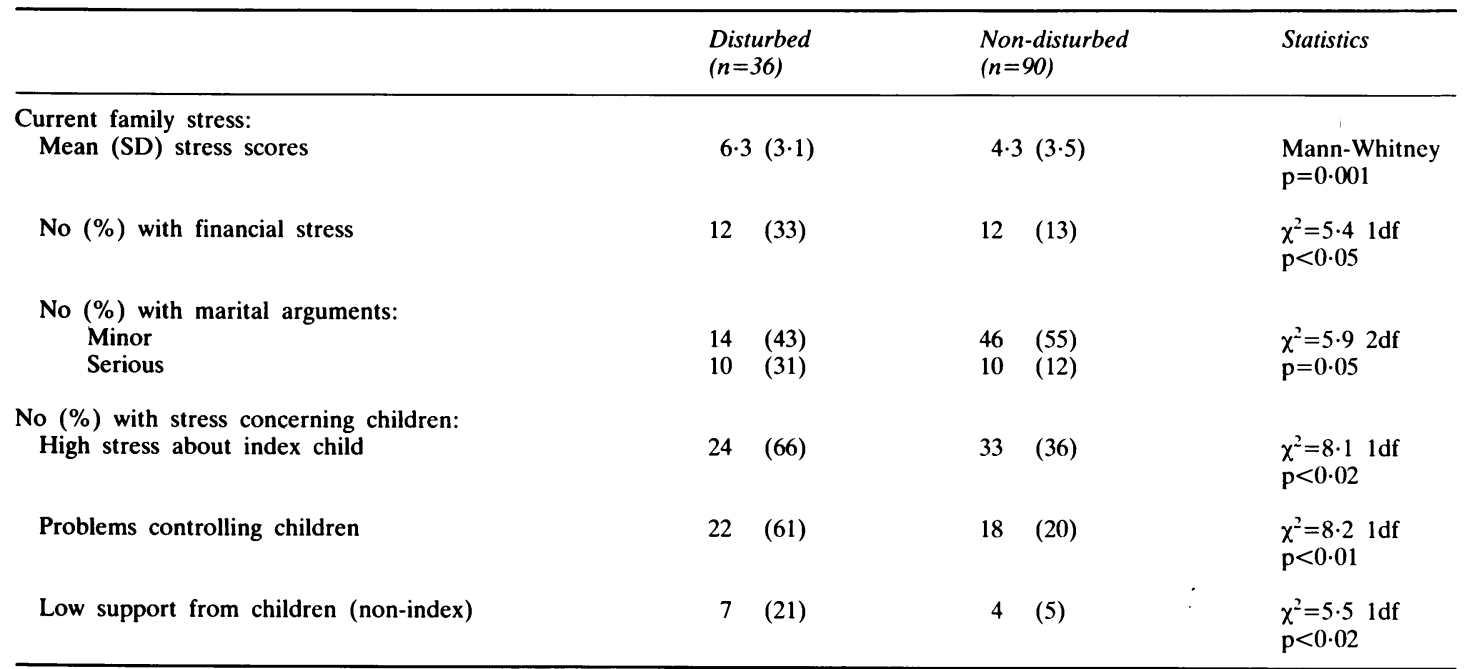

\section{PSYCHOSOCIAL BACKGROUND IN DISTURBED}

\section{CHILDREN}

Psychosocial disturbance, particularly a disturbed family background, tends to be an associated feature of childhood psychiatric disturbance. We were interested in establishing which specific psychological problems are of relevance for childhood psychiatric disturbances as it presents in the general paediatric setting.

There were no significant socioeconomic differences between disturbed and non-disturbed children, although unemployment of parents was slightly more common in the disturbed group (nine $(25 \%)$ compared with nine $(10 \%))$. But more disturbed children came from broken homes (14 (39\%) compared with $\left.15(17 \%) ; \chi^{2}=5.9 \mathrm{ldf} ; \mathrm{p}=0 \cdot 01\right)$, their mothers reported current 'nerve' problems more often (10 $(27 \%)$ compared with six $(6 \%) ; \chi^{2}=8.5$ Idf, $\mathrm{p}<0.01)$, they had higher scores on the general health questionnaire (mean (SD) 4.3 (5.9) compared with $1.8(3.9), p=0.01)$, and fewer mothers were in outside employment $(11 / 32(34 \%)$ compared with $61 / 84(72 \%) ; \chi^{2}=10$ ldf, $\left.\mathrm{p}<0.01\right)$.

At the time of assessment mothers in the disturbed group felt under more general psychosocial stress as measured in the social stress and support interview (table 3), and they noted more financial stress and marital difficulties. Out of the four psychosocial areas explored in this interview, however, most stress was scored by the mothers in relation to index children; they reported more problems in controlling the children and they were experiencing less support from them.

\section{Discussion}

Using detailed parental interviews to assess child psychiatric disorder, we found this to be present in $28 \%$ of children aged 7 to 12 years referred to general paediatric clinics. Previous studies and our own data from parental questionnaire information have reported slightly higher rates $(35 \%$ on the Rutter parental scale $\left.A^{9}{ }^{10}\right)$. This, together with the modest predictive value of the questionnaires, indicates a trend for them to overestimate disturbance in paediatric samples.

Our rates of disorder from the parental interviews were appreciably higher than in general population samples of children of comparable age and psychosocial backgrounds. Thus in the Isle of Wight study, Rutter et al identified $12 \%$ of all children as psychiatrically disturbed. ${ }^{19}$ This in itself strongly suggests that disturbed children are more likely to attend paediatric clinics than non-disturbed children. The high rates in our sample are close to those reported for adult patients admitted to medical wards, ${ }^{8}$ and they are only marginally higher than for children attending general practice ${ }^{11}$; this indicates that the link between psychiatric disturbance and medical help seeking is of comparable order in primary and secondary medical settings and shows similarities across the age range.

By far the most common psychiatric diagnosis in our sample was emotional disorder, thus confirming a special affinity between emotional-as opposed to antisocial-and physical symptoms. ${ }^{11}$ Inquiry about symptoms such as worrying, fears, irritability, and 
problems in relationships with mothers, siblings, and peers as well as about restlessness and overactivity is likely to be productive in assessing psychiatric disturbance at the paediatric clinic. Some of the other emotional symptoms present in the disturbed group (obsessionality, worrying about health, school refusal) are of interest because they are quite uncommon among disturbed children in other settings such as children attending child psychiatric clinics (data from the study reported in Garralda and Bailey ${ }^{20}$ ) and may be specifically related to a 'psychosomatic' tendency to overemphasise somatic over psychological symptoms as a response to stress or difficulty. Similarly, long psychiatric histories were particularly conspicuous in this sample and this may indicate that the psychiatric disturbance may be an exaggeration of temperamental difficulties or lifelong traits perhaps associated with a 'psychosomatic' tendency in some of these children.

We found few differences between disturbed and non-disturbed children in types of presenting physical complaints, nor were there difficulties in background physical conditions or in recent contacts with medical services. The only difference was in the global and non-specific health measure of energy level: disturbed children were not only more commonly described as 'bounding with energy', but they were also more apathetic or lethargic than the rest. Energy level stands out therefore as a symptom which may alert paediatricians to the presence of childhood psychiatric disorder.

In terms of the psychosocial associations of psychiatric disorder, our sample was comparable with those in general population studies. ${ }^{21}$ Broken homes, current maternal mental health problems, and marital difficulties were more common in the disturbed group. This highlights the importance that these issues and their possible influence on the children's psychological and physical health be recognised as part of the global paediatric assessment.

As in our general practice study, ${ }^{11}$ we also found an association between disturbance and family stress. Family stress has been previously found to be associated with increased consultations for children's complaints. ${ }^{22} 23$ In the present study the general stress felt by mothers in the disturbed group about their children was higher than for other psychosocial areas explored and difficulties in controlling the children were a major concern for them. This is likely to have contributed to the consultations by sensitising parents to the somatic symptoms and by decreasing their confidence in dealing with the problem or in controlling the situation.

There is evidence that high levels of encouragement and empathy by paediatricians lead to both satisfaction and reduction in concern in mothers. ${ }^{24}$ Specific empathic and encouraging statements by doctors could also help boost the mother's confidence and would be especially appropriate for parents of disturbed children attending general paediatric clinics.

The authors wish to thank Drs K Adler, A Bradbury, J Couriel, J Owens, S Roberts, and A Robinson and their staff for their cooperation and assistance in this study. They are also grateful to Professor R Boyd for his comments. The research was funded by a grant from the North West Regional Health Authority.

\section{References}

1 Coleman JV, Patrick DL, Baker SM. The mental health of children in an HMO program. $J$ Pediatr 1977;91:150-3.

2 Jacobson AM, Goldberg ID, Burns BJ, Hoeper EW, Hankin JR, Hewitt K. Diagnosed mental disorder in children and use of health services in four organized health care settings. Am J Psychiatry 1988;137:559-65.

3 Starfield B, Gross E, Wood M, et al. Psychosocial and psychosomatic diagnoses in primary care of children. Pediatrics 1980;66:159-67.

4 Goldberg ID, Regier DA, McInerny TK, Pless IB, Roghmann $\mathrm{KJ}$. The role of the pediatrician in the delivery of mental health services to children. Pediatrics 1979;63:898-909.

5 Goldberg ID, Claus J, Roghmann J, McInerny TK, Burke JD. Mental health problems among children seen in pediatric practice: prevalence and management. Pediatrics 1984;73:278-93.

6 McClune D, Richardson MM, Powell JA. Psychosocial health issues in paediatric practices: parents, knowledge and concerns. Pediatrics 1984;74:183-90.

7 Starfield B, Borkowf S. Physician's recognition of complaints made by parents about their children's health. Pediatrics 1969;43:168-72.

${ }^{8}$ Nabarro J. Unrecognised psychiatric illness in medical patients. Br Med J 1984;289:635-6.

${ }^{9}$ Fitzgerald M. Behavioural deviance and maternal depressive symptoms in paediatric outpatients. Arch Dis Child 1985;60:560-2.

10 Cundall DB. Children and mothers at clinics: who is disturbed? Arch Dis Child 1987;62:820-4.

1 Garralda ME, Bailey D. Children with psychiatric disorders in primary care. J Child Psychol Psychiatry 1986;27:611-24.

12 Rutter M, Tizard J, Whitmore $\mathrm{K}$, eds. Education, health and behaviour. London: Longman, 1970.

13 World Health Organisation. International classification of diseases. 9th revision. Geneva: WHO, 1975.

14 Goldberg D. Manual of the general health questionnaire. Windsor: National Foundation of Education Research, 1978.

15 Jenkins R, Mann HA, Belsey E. The background, design and use of a short interview to assess social stress and support in research and clinical settings. Soc Sci Med 1981;15:195-203.

16 Bailey D, Garralda ME. The use of the social stress and support interview in families with deviant children: methodological issues. Soc Psychiatry 1987;22:209-15.

17 World Organization of National Colleges, Academies, and Academic Associations of General Practitioners/Family Physicians. International classification of health problems in primary care (ICHPPC-2 defined.) 3rd ed. Oxford: Oxford University Press, 1983.

${ }^{18}$ Garralda ME, Bailey D. Psychosomatic problems in the general paediatric clinic. J Psychosom Res (in press).

19 Rutter M, Cox A, Tupling C, Berger M, Yule W. Attainment and adjustment in two geographical areas. $I$. The prevalence of psychiatric disorder. Br J Psychiatry 1975;126:493-509. 


\section{Psychiatric disorders in general paediatric referrals 1733}

${ }^{20}$ Garralda ME, Bailey D. Child and family factors associated with referral to child psychiatrists. Br J Psychiatry 1988;153:81-9.

21 Wolkind S, Rutter M. Separation, loss and family relationships. In: Rutter M, Hersov LA, eds. Child and adolescent psychiatry, modern approaches. 2nd ed. Oxford: Blackwell Scientific Publications, 1985:.

22 Mechanic D. The influence of mothers on their children's health attitudes and behaviour. Pediatrics 1964;33:444-53.

${ }^{23}$ Roghmann KJ, Haggerty RJ. Family stress and the use of health services. Int J Epidemiol 1972;1:279-86.
${ }^{24}$ Wasserman RC, Barriatua RD, Carter WB, Lippincott BA. Pediatric clinician's support for parents makes a difference: an outcome based analysis of clinician parent interaction. Pediatrics 1984;74:1047-53.

Correspondence to Dr ME Garralda, Department of Child Psychiatry, Lane Building, Booth Hall Children's Hospital, Charlestown Road, Blackley, Manchester M9 2AA.

Accepted 2 August 1989 